\title{
СТРАТЕГИИ БЕЗОПАСНОСТИ РОССИИ В КОНТЕКСТЕ БИФУРКАЦИИ
}

\author{
(C) 2021 г. Е. В. Поликарпова, В. С. Поликарпов, А. Г. Байбуз \\ Южнный федеральный университет, г. Ростов-на-Дону, Россия
}

Цель исследования. Статья посвящена исследованию спектра стратегий безопасности России в зоне бифуркащии.

Методология исследования основывается на кониепииях материалистической диалектики, сочиологической теории сочиальных систем Н. Лумана, способа жизнеобеспечения как единства способа производства материальных благ и способа безопасности, «парадоксальной» (диалектической) логики и цивилизационной войны; также используются методы сравнительного анализа и конщепщчи стратегий безопасности США, Китая и России.

Результаты исследования. Показано, что особенности иелого спектра стратегий национальной безопасности России вытекают из парадоксального, «невозможного» характера ее циивилизации и истории, отличающихся от «стандартной» истории других циивлизащий Запада, Индии, Китая, Японии и др., и обусловлень существованием человечества в контексте бифуркации с ее сильной социальной турбулентностью и весьма малой предсказуемостью будущих событий; показан спектр стратегий безопасности России.

Перспективы исследования. Полученные результаты могут использоваться в дальнейших исследованиях ряда стратегий безопасности России.

Ключевые слова: стратегия; бифуркация; ичивилизащия; война; безопасность; диалектика; империя; Россия.

\section{RUSSIA'S SECURITY STRATEGIES IN THE CONTEXT OF BIFURCATION}

\section{(C) 2021 E. V. Polikarpova, V. S. Polikarpov, A. G. Baibuz \\ Southern Federal University, Rostov-on-Don, Russia}

The aim of the study. The article is devoted to the study of the Russian security strategies spectrum in the bifurcation zone.

The research methodology is based on the concepts of materialistic dialectics, N. Luhmann's sociological theory of social systems, the life support method as a unity of the material goods production and the security methods, "paradoxical» (dialectical) logic and civilizational war, also used are the methods of comparative analysis, as well as the concepts of the security strategy of the United States, China and Russia.

Research result. It is shown that the features of a whole range of national security strategies of Russia arise from the paradoxical, «impossible» nature of its civilization and history, which differ from the "standard» history of other civilizations of the West, India, China, Japan, etc., and are due to the existence of humanity in the context of bifurcation with its strong social turbulence and very little predictability of future events. 
Research perspectives. The obtained results can be used in further study of a number of Russian security strategies.

Key words: strategy; bifurcation; civilization; war; security; dialectics; empire; Russia.

Введение. В начале 10-х годов XXI столетия человечество вошло в фазу бифуркации. Эта фаза характеризуется значительным усложнением системы информационно-сетевого общества из-за развития новейших технологий, а также сильной турбулентностью и непредсказуемостью будущего. Данные изменения требуют адекватных обновленных стратегий безопасности. Более того, значимость новых стратегий и переосмысление старых в соответствии с вызовами эпохи обусловлены возвращением на международную арену империй: Американской, Российской и Китайской империи «Красного дракона» $[3,10]$. Все это касается и нынешней России, которая оказалась перед лицом новых вызовов. Постоянно изменяющиеся реалии современной эпохи требуют использования адекватных стратегий безопасности. Здесь нами используется дефиниция стратегии, сформулированная Г.Г. Почепцовым в монографии «Стратегия». В этой книге дается подробный анализ стратегии как удела сильных игроков, которые способны эффективно осуществлять оптимизацию управления будущим [12]. Действенность стратегии обусловлена тем, что она позволяет осуществлять интеллектуальное сопровождение перехода из пункта настоящего в пункт будущего и накапливать потенциал будущего в настоящем. Иными словами, стратегия вместе со своим инструментарием вырабатывается на протяжении длительного времени благодаря имеющимся интеллектуальным, темпоральным, технологическим и прочим ресурсам страны, государства, цивилизации. В противном случае, подчеркивает Г. Почепцов, страна или цивилизация начинает существовать на более простом уровне и двигаться по траектории чужой цивилизации со всеми вытекающими из этого нежелательными последствиями [12]. Определение, представленное в монографии, подходит для выявления целого спектра стратегий национальной безопасности России в нынешних условиях.
Методология исследования. Существенными в ходе аналитического рассмотрения спектра стратегий безопасности России являются их теоретико-методологические основания, которые дают возможность понимать их эффективность. Выделим четыре таких основания:

1) универсальная социологическая теория Н. Лумана [8];

2) выдвинутая Р. Дж. Блэкберном концепция способа жизнеобеспечения общества, представляющая собой единство способа производства материальных благ и способа безопасности (оборона, нападение, дипломатия, разведка и пр.), направленного на противодействие деструктивным действиям другого социума [2];

3) диалектический характер большой стратегии в условиях «постгероической войны», обоснованный специалистом в области стратегии Э.Н. Люттваком [9];

4) разработанная Б. Лидделом Гартом концепция «стратегии непрямых действий», главным персонажем которой является Ноmо Strategicus (человек стратегический) [7].

Теоретический аспект. В настоящее время крупные державы мира серьезное внимание уделяют своим национальным стратегиям безопасности. Здесь будут рассмотрены особенности стратегий Российской Федерации, Соединенных Штатов Америки и Китайской Народной Республики. При формировании стратегии национальной безопасности России учитываются следующие долгосрочные приоритеты национальных интересов: оборона страны, государственная и общественная безопасность, повышение качества жизни российских граждан, экономический рост, наука, технологии и образование, здравоохранение, культура, экология живых систем и рациональное природопользование, стратегическая стабильность и равноправное стратегическое партнерство [14]. Неявным теоретико-методологическим основанием здесь выступают 
законы диалектики и практика информационного общества.

Заслуживает внимания недавно принятая в США «промежуточная стратегия национальной безопасности». В ней подчеркивается, что Америка не будет принимать участия в «вечных войнах», и отмечается необходимость обеспечить кибербезопасность, а также говорится о том, что появились «новые угрозы» и «беспрецедентные вызовы»: противостояние с Китаем, изменение климата, процессы в Индо-Тихоокеанском регионе [16]. Теоретико-методологическим основанием здесь выступают прагматизм и формальная логика.

Стратегия национальной безопасности Китая имеет классический смысл. Она опирается на комплексную мощь страны, призванную обеспечить защиту социалистической системы и руководящей линии КПК, населения, государства, военной системы, государственных границ и достоинства страны, «мир во всем мире», а также ликвидацию традиционного дефицита ресурсов, поддержание социального порядка и благосостояния нации [4]. Теоретико-методологическое основание концепции национальной безопасности Китая - это материалистическая диалектика (на XIX съезде КПК Си Цзиньпин прижизненно объявлен классиком марксизма-ленинизма) и этика Конфуция, не совместимая с ценностями «эгоистичного» Запада.

В плане нашего исследования представляет большой интерес универсальная социологическая теория Н. Лумана, адекватная развивающемуся нелинейному информационно-сетевому обществу. Значимость теории состоит в том, что она позволяет выяснить сущность рисков (небезопасности) вообще и в системе безопасности социума в частности. Не менее важным является совершенно иное понимание существования мира не как действие субъекта, а как бессубъектный социальный процесс [8]. Именно данный бессубъектный социальный процесс должна принимать во внимание правящая элита России, проектирующая спектр стратегий безопасности нашей страны. Парадигма бессубъектного социального процесса просматривается в отечественных научных исследованиях, посвященных анализу различных систем безопасности - социальной, экономической, финансовой, экологической, энергетической, военной, информационной, кибернетической и других. Функционирование всех этих видов систем безопасности связано с существованием и развитием всемирной «среды знаний» («компьютеризованного интеллекта»), что привело к исключению человека как субъекта деятельности и к трактовке мира как мультицентричного феномена (фактически речь идет о «многополюсном мире») [8].

Заслуживают внимания исследования западного ученого Р. Дж. Блэкберна. В статье «Геополитика и способ безопасности» он подчеркивает, что не существует прямой корреляции между способом производства материальных благ и способом безопасности - общество способно иметь мощный способ безопасности при отсталом способе производства или иметь процветающую экономику при уязвимости способа безопасности [2]. В данном случае показан примат геополитического фактора в развитии цивилизации (конкретного общества) перед экономической детерминантой. Это следует учитывать при рассмотрении спектра стратегий безопасности России (здесь именно геополитика доминирует над экономикой) в сравнении со спектрами стратегий Запада и других стран мира.

Следует принять во внимание вывод, следующий из тщательного анализа Э.Н. Люттваком существенных особенностей значимости стратегии, а также логики войны и мира. Coгласно этому выводу США достигли кульминации в своем могуществе на пороге краха советской системы: переход этой точки кульминации закончится спадом могущества или влияния [9]. Это означает, что России следует использовать диалектическую («парадоксальную») логику войны и мира в противостоянии США, которые теряют сейчас (в 2021 году) свою мировую гегемонию.

Весьма оригинальным и значимым в области стратегии является труд Б. Лиддела Гарта «Стратегия непрямых действий». Он представляет собой богатейший сконцентрированный опыт человечества в области стратегии и тактики - так называемую энциклопедию «свода непрямых действий» [7]. Данная концепция «стратегии непрямых действий» используется в идущей сейчас «гибридной», «ментальной войне» Запада против 
России. Эти моменты необходимо учитывать при разработке и применении спектра стратегий безопасности России.

В ходе выяснения спектра стратегий безопасности современной России следует принимать во внимание парадоксальный, «невозможный» и проектный характер истории нашей страны [13]. Это означает, что спектр стратегий безопасности, прежде всего, определяется сформулированной В. Путиным «Большой стратегией России» - стратегией реванша, то есть возвращением великодержавного (суверенного) статуса, обеспечивающего процветание страны.

Спектр стратегий безопасности России. Теперь более подробно рассмотрим существующий спектр стратегий безопасности России, которая, прежде всего, носит комплексный характер и использует такие новые технологи, как искусственный интеллект, видеоаналитика, цифровые трансформации, Интернет вещей и пр. Вполне логично, что в России была выработана стратегия комплексной безопасности ноосферного типа, понятие о которой разработано отечественными исследователями М.С. Алешенковым и Б.Н. Родионовым [1].

Представляет немалый интерес такая стратегия безопасности России, как темпоральная (и пространственная) модель управления обществом. В различных своих версиях она описывает спиральный характер истории человечества. Одной из таких версий является модель неархимедова времени, позволяющая элитам Южной Кореи, Сингапура и других азиатских стран конструировать необходимый им грядущий общественный строй, адекватный вызовам будущего.

Следующая значимая стратегия безопасности России - система образования. Умелое использование своего интеллектуального потенциала и достижений советской цивилизации в сфере культуры и образования в контексте новейших информационных технологий играет решающую роль в существовании и развитии нашей страны.

Немаловажной стратегией безопасности России является идеология. Это мощная мобилизующая сила, важнейший инструмент нормальной жизнедеятельности государства, общества и личности. Западный политолог
Дж. Шварцмантель в книге «Идеология и политика» обосновал несколько важных положений. Во-первых, идеология в современной международной политической жизни - это не только позиционирование государств, но и обязательное условие их выживания. Во-вторых, положение «идеи движут миром» имеет ключевое значение в жизни людей и государства, потому что оно определяет приоритеты, ценности и цели развития. В-третьих, разрушение государства и уничтожение наций всегда начиналось и сопровождалось кризисом идеологии и системы ценностей, идеологическая борьба иногда опаснее применения ядерного оружия. Идеологическая победа не менее важна, чем политическая или экономическая, борьба за сознание миллионов людей становится все более актуальной [15].

Идеология современной России просматривается в ее версии цифровой экономики, основанной на операции «максимума» («идемпотентности») вместо действия «сложения», используемого в обычной модели межотраслевого баланса [6]. Именно идемпотентность теперь стала играть важную роль в экономике с ее цифровыми технологиями, причем она выражает неконкурентность в потреблении общественного продукта для всех потребителей.

Весьма значимой стратегией безопасности России может выступать такая взаимосвязь философии управления и философии безопасности, которая в определенном плане означает их тождественность [11].

Не следует сбрасывать со счетов и достижения советской цивилизации, далеко опередившей развитие остального человечества и способной выступать как наследие в качестве стратегии безопасности России. Отечественный политолог и социолог С. Кара-Мурза в своей фундаментальной монографии «Советская цивилизация» раскрывает ее сущность с особым взглядом на мир, человека, власть и хлеб. Советская цивилизация зародилась в недрах общинного крестьянского коммунизма и помогла России выйти из исторической ловушки, куда ее загнал Запад, открыв народу простор для такого развития ума, силы и духа, что потерпел поражение крестовый поход тоталитарной тевтонской силы [5]. Геополитическая катастрофа Сoветского Союза показала подлинную, гума- 
нистическую суть советской цивилизации, дала народу знание и понимание, оплаченные страданиями сотен миллионов человек, очертила контуры нового проекта, будущего жизнеустройства нашей страны.

Наконец, последней по счету, но не по значению, стратегией безопасности России является наличие у нас мощной армии, считающейся одной из самых сильных в мире, ведь наши вооруженные силы способны вести войну, адекватную цифровой эпохе: это интернет, «умные дома», цифровые платформы и другие технологии. Так как все цифровое пространство едино, то на первый план выходит новая цифровая война (кибервойна). Если государство не контролирует свои каналы связи, то все критические технологии могут быть отключены. Государство должно обладать цифровым суверенитетом, обеспечивая тем самым свою безопасность. Сейчас Россия находится на пороге нового цифрового суверенитета, совершенно нового типа войны, которая опаснее применения ядерного оружия. Очень опасной является манипуляция цифровым пространством, в котором нельзя установить адрес атаки, поэтому, как подчеркивает в одном из интервью экс-полковник внешней разведки А. Безруков, страна должна иметь суверенитет в своем киберпространстве. И Россия его имеет, являясь одной из немногих стран, обладающих уникальными технологиями. В силу происходящего сейчас важного передела влияния в мире, прежде всего в сфере технологий (война США и Китая), защищенность киберпространства имеет важнейшее значение. Стратегия военной безопасности России должна принимать во внимание все особенности современной ситуации, учитывая невозможность провести границы между миром и войной.

Заключение. Все изложенное выше свидетельствует о том, что спектр стратегий безопасности России включает в себя следующие составляющие: комплексный характер безопасности России; темпоральную стратегию - модель управления обществом (модель неархимедова времени); систему образования; значение идеологии; цифровую экономику как экономическую идеологию; тождество философии управления и философии безопасности; наследие советской цивилиза- ции; значимость вооруженных сил. Выводы, сделанные в ходе исследования, целесообразно использовать в дальнейших исследованиях ряда стратегий безопасности России.

\section{Литература}

1. Алешенков М. С. Основы комплексной безопасности ноосферных систем, их объектов и субъектов. - М.: Моск. акад. комплекс. безопасности предпринимательства, 2000. $202 \mathrm{c}$.

2. Блэкберн Р. Дж. Геополитика и способ безопасности // Война и геополитика. 3-й выпуск Альманаха «Время мира» / Под ред. Н.С. Розова. - Новосибирск, НГУ, 2003. $571 \mathrm{c}$.

3. Вдовиченко Л.Н. Социальные отношения в турбулентное время // Социс. 2012. — №9. - C. 13-16.

4. Голуенко Т.А., Степанова О.В. Основные направления концепции национальной безопасности Китая // Наука и образование Большого Алтая. - 2018. - Вып. 1. C. 38-41.

5. Кара-Мурза С. Советская цивилизация. - М.: Родина, 2019. - 1280 с.

6. Козырев А.Н. Моделирование, НТП, упорядоченность и цифровая экономика // Экономика и математические методы. 2011. - T. 47. - №4. - С. 131-142.

7. Лиддел Гарт Б. Стратегия непрямых действий. - М.: Астрель; Владимир: ВКТ, 2012. - $508 \mathrm{c}$.

8. Луман Н. Социальные системы. Очерк общей теории. - СПб.: «Наука», 2007. $643 \mathrm{c}$.

9. Люттвак Э. Н. Стратегия: логика войны и мира. - М.: Русский Фонд Содействия Образованию и Науке, 2012. - 392 с.

10. Мюнклер Г. Империи. Логика господства над миром: от Древнего мира до США. М.: Кучково поле, 2015. - 400 с.

11. Поликарпов В.С. Философия управления (эссе). - Ростов-на-Дону, Таганрог: Изд-во ТРТУ, 2001. - 186 с.

12. Почепцов Г.Г. Стратегия. - М.: «Рефл-бук», К: «Ваклер», 2005. - 377 с.

13. Смирнов И. И. Тропы истории. Криптоаналитика глубинной власти. - М.: Товарищество научных изданий КМК, 2020. $473 \mathrm{c}$. 
14. Стратегия национальной безопасности Российской Федерации. Указ Президента Российской Федерации от 31 декабря 2015 г.

15. Шваримантель Дж. Идеология и политика. - Харьков: Гуманитарный центр, 2009. - 312 c.

16. Interim National Security Strategic Guidance [Electronic resource] // White House. URL: https://www.whitehouse.gov/wp-content/ uploads/2021/03/NSC-1v2.pdf (Date accessed: 13.04.2021).

\section{References}

1. Aleshenkov M.S. Osnovy kompleksnoj bezopasnosti noosfernyh sistem, ih ob'ektov i sub'ektov [Fundamentals of complex security of noospheric systems, their objects and subjects]. - Moscow: Mosk. akad. kompleks. bezopasnosti predprinimatel'stva, 2000. - $202 \mathrm{p}$.

2. Bljekbern R. Dzh. Geopolitika i sposob bezopasnosti [Geopolitics and the way of security] // Vojna i geopolitika. 3-j vypusk Al'manaha «Vremja mira» [War and Geopolitics. 3rd issue of the Almanac «Time of the World»] / In N.S. Rozov (eds.). - Novosibirsk, NGU, 2003. - $571 \mathrm{p}$.

3. Vdovichenko L.N. Social'nye otnoshenija $\mathrm{v}$ turbulentnoe vremja [Social relations in turbulent time] // Socis. - 2012. — №9. — Pp. 13-16.

4. Goluenko T.A., StepanovaO.V. Osnovnye napravlenija koncepcii nacional'noj bezopasnosti Kitaja [The main directions of the concept of national security of China] // Nauka i obrazovanie Bol'shogo Altaja [Science and education of the Greater Altai]. - 2018. - Issue 1. - Pp. 38-41.

5. Kara-Murza S. Sovetskaja civilizacija [Soviet civilization]. - Moscow: Rodina, 2019. - $1280 \mathrm{p}$.

6. Kozyrev A.N. Modelirovanie, NTP, uporjadochennost' i cifrovaja jekonomika [Modeling, STP, orderliness and digital economy] // Jekonomika i matematicheskie metody [Eco- nomics and Mathematical methods]. — 2011. Vol.47. — №4. - Pp. 131-142.

7. Liddel Gart B. Strategija neprjamyh dejstvij [Strategy of indirect actions]. - Moscow: Astrel'; Vladimir: VKT, 2012. - 508 p.

8. Luman N. Social'nye sistemy. Ocherk obshhej teorii [Social systems. An outline of the general theory]. - Saint Petersburg: «Nauka», 2007. - 643 p.

9. Ljuttvak Je. N. Strategija: logika vojny i mira [Strategy: the logic of war and Peace]. Moscow: Russkij Fond Sodejstvija Obrazovaniju i Nauke, 2012. - 392 p.

10. Mjunkler G. Imperii. Logika gospodstva nad mirom: ot Drevnego mira do SShA [Empires. The logic of domination over the world: from the Ancient World to the USA]. - Moscow: Kuchkovo pole, 2015. - 400 p.

11. Polikarpov V.S. Filosofija upravlenija (jesse) [Philosophy of management (essay)]. Rostov-on-Don, Taganrog: Izd-vo TRTU, 2001. - $186 \mathrm{p}$.

12. Pochepcov G. G. Strategija [Strategy]. - Moscow: «Refl-buk», Kiev: «Vakler», 2005. - 377 p.

13. Smirnov I.I. Tropy istorii. Kriptoanalitika glubinnoj vlasti [Trails of History. Cryptanalytics of deep power]. - Moscow: Tovarishhestvo nauchnyh izdanij KMK, 2020. — 473 p.

14. Strategija nacional'noj bezopasnosti Rossijskoj Federacii. Ukaz Prezidenta Rossijskoj Federacii ot 31 dekabrja 2015 g. [The National Security Strategy of the Russian Federation. Decree of the President of the Russian Federation of December 31, 2015].

15. Shvarcmantel'Dzh. Ideologija i politika [Ideology and politics]. - Harkov: Gumanitarnyj centr, 2009. - $312 \mathrm{p}$.

16. Interim National Security Strategic Guidance [Electronic resource] // White House. URL: https://www.whitehouse.gov/wp-content/ uploads/2021/03/NSC-1v2.pdf (Date accessed: 13.04.2021). 


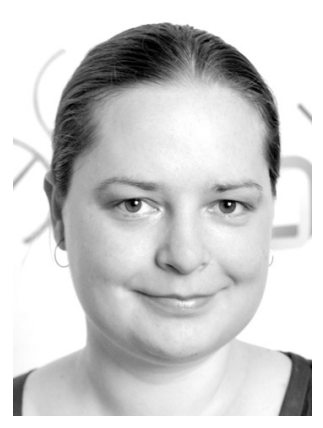

Поликарпова Елена Витальевна - доктор философских наук, доцент, профессор кафедры философии Института управления в экологических, экономических и социальных системах Южного федерального университета.

Polikarpova Elena Vitalievna - Doctor of Philosophical Sciences, Professor of the Department of Philosophy, Institute of Management in Economic, Ecological and Social Systems, Southern Federal University.

344018, г. Ростов-на-Дону, ул. Черепахина, 249, кв. 110 249 Cherepahina st, app. 110, 344018, Rostov-on-Don, Russia E-mail: nellenele@gmail.com

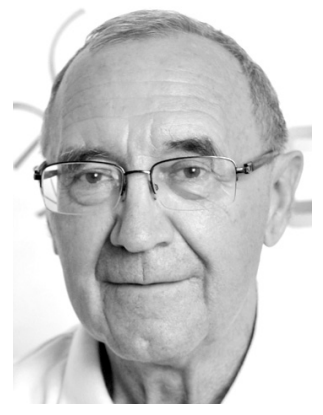

Поликарпов Виталий Семенович - доктор философских наук, профессор Южного федерального университета.

Polikarpov Vitaly Semenovich - Doctor of Philosophical Sciences, Professor, Southern Federal University.

347922 , г. Таганрог, Некрасовский пер., 44 44 Nekrasovskiy ln., 347922, Taganrog, Russia

E-mail: vspolikarp@gmail.com

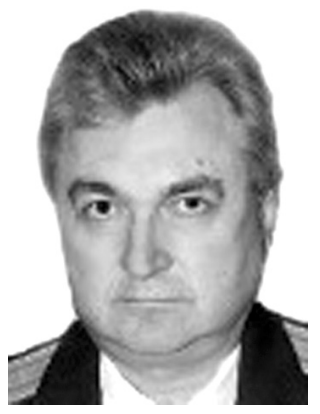

Байбуз Андрей Геннадьевич - полковник, заместитель начальника кафедры радиоэлектронной борьбы Военного учебного центра Южного федерального университета.

Baibuz Andrey Gennadievich - Deputy Head of the Department of Electronic Warfare, Southern Federal University.

347922 , г. Таганрог, Некрасовский пер., 44

44 Nekrasovskiy ln., 347922, Taganrog, Russia

E-mail: abaybuz@sfedu.ru 